\title{
Activation of C3a receptor is required in cigarette smoke-mediated emphysema
}

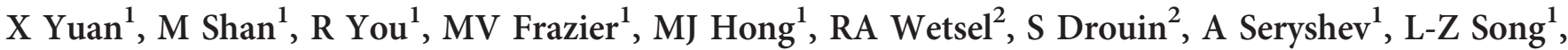 \\ L Cornwell $^{3}$, RD Rossen ${ }^{1,4,5}$, DB Corry ${ }^{1,4,5,6}$ and F Kheradmand ${ }^{1,4,5,6}$
}

Exposure to cigarette smoke can initiate sterile inflammatory responses in the lung and activate myeloid dendritic cells (mDCs) that induce differentiation of T helper type 1 (Th1) and Th17 cells in the emphysematous lungs. Consumption of complement proteins increases in acute inflammation, but the contribution of complement protein 3 (C3) to chronic cigarette smoke-induced immune responses in the lung is not clear. Here, we show that following chronic exposure to cigarette smoke, C3-deficient $\left(C 3^{-/-}\right)$mice develop less emphysema and have fewer $\mathrm{CD} 11 \mathrm{~b}^{+} \mathrm{CD} 11 \mathrm{c}{ }^{+}$mDCs infiltrating the lungs as compared with wild-type mice. Proteolytic cleavage of $\mathrm{C} 3$ by neutrophil elastase releases $\mathrm{C} 3 \mathrm{a}$, which in turn increases the expression of its receptor (C3aR) on lung mDCs. Mice deficient in the C3aR $\left(\mathrm{C}^{\mathrm{a}} \mathrm{ar}^{-{ }^{-}}\right.$) partially phenocopy the attenuated responses to chronic smoke observed in $\mathrm{C}^{-1-}$ mice. Consistent with a role for C3 in emphysema, C3 and its active fragments are deposited on the lung tissue of smokers with emphysema, and smoke-exposed mice. Together, these findings suggest a critical role for $\mathrm{C} 3 \mathrm{a}$ through autocrine/paracrine induction of $\mathrm{C} 3 \mathrm{aR}$ in the pathogenesis of cigarette smoke-induced sterile inflammation and provide new therapeutic targets for the treatment of emphysema.

\section{INTRODUCTION}

Exposure to cigarette smoke and/or other toxic environmental agents can initiate sterile inflammation in the lungs of asymptomatic smokers. Animal models have confirmed a causal role for smoke in lung destruction. ${ }^{1,2}$ Activation of the immune system also occurs in atherosclerosis and lung cancer, two other diseases associated with cigarette smoking, suggesting that immune mediators that promote sterile inflammation may play a significant role in the pathophysiology of these diseases as well. ${ }^{3,4}$

Acute exposure to cigarette smoke induces rapid recruitment of neutrophils into the airways, a process that requires signaling through TLR4, upregulation of interleukin 1 receptor 1 (IL-1R1), and activation of inflammasome pathways. ${ }^{5,6}$ Cigarette smokeactivated alveolar macrophages produce IL-1 $\beta$ that helps to perpetuate lung inflammation; with time, the inflammation becomes independent of TLR4 signaling. ${ }^{5,7}$ Thus, although it is clear that acute cigarette smoke exposure activates early pro-inflammatory pathways, the additional stimuli that, even after smoke inhalation stops, cause this inflammatory response to persist and induce acquired immune responses to lung tissue elements remain poorly understood.

Recently, we and others have reported suggestive evidence that support how cigarette smoking may induce autoimmune responses in humans and animal models of emphysema. ${ }^{2,8}$ Specifically, in addition to neutrophils and macrophages, cellular elements of the innate immune system, we and others have shown that adaptive immune responses involving $\mathrm{T}$ helper type 1 (Th1) and Th17 cells are a prominent feature of the pulmonary response to smoke in current and former smokers with emphysema; ${ }^{9-11}$ the presence of autoreactive $\mathrm{T}$ cells is associated with decline in lung function. ${ }^{12}$ Similarly chronic exposure to cigarette smoke increases the numbers of Th17 cells in the lungs and fosters emphysema in mice. ${ }^{10,13}$ Consistent with a pathogenic role for Th17 cells in emphysema, genetic ablation of IL-17A or IL-17R protects mice against

\footnotetext{
${ }^{1}$ Department of Medicine, Baylor College of Medicine, Houston, Texas, USA. ${ }^{2}$ Brown Foundation Institute of Molecular Medicine-Research Center for Immunology and Autoimmune Diseases, The University of Texas Medical School at Houston, Houston, Texas, USA. ${ }^{3}$ Department of Surgery, Baylor College of Medicine, Houston, Texas, USA. ${ }^{4}$ Department of Pathology and Immunology, Baylor College of Medicine, Houston, Texas, USA. ${ }^{5}$ Michael E DeBakey VA Center for Translational Research on Inflammatory Diseases, Houston, Texas, USA and ${ }^{6}$ Biology of Inflammation Center, Baylor College of Medicine, Houston, Texas, USA. Correspondence: DB Corry or F Kheradmand (dcorry@bcm.edu or farrahk@bcm.edu)
} 
smoke-induced emphysema. ${ }^{10,14,15}$ The mechanisms responsible for recruitment and activation of myeloid dendritic cells (mDC) in response to cigarette smoke are not well understood. ${ }^{10,16}$ Although both Th1 and Th17 cells are critical in emphysema pathogenesis, activated mDCs expressing high levels of MHC-II, CD11b, and CD11c drive the differentiation of these pathogenic $\mathrm{T}$ cells and can alone induce disease when transferred to naïve mice. ${ }^{10}$

Collectively, the complement proteins, among the most potent and heavily regulated innate immune factors, play key roles in acute and chronic inflammatory responses. ${ }^{17}$ In particular, complement protein 3 (C3), an essential component of the host defense system, has been shown to provide some of the most potent chemotactic responses in acute inflammation. ${ }^{18,19} \mathrm{C} 3 \mathrm{a}$, an active cleaved product of $\mathrm{C} 3$, binds to its receptor $(\mathrm{C} 3 \mathrm{aR})$, a seven transmembrane signaling molecule expressed on $\mathrm{mDCs}$, and is essential in development of allergic lung inflammation and in models of acute pneumonia. ${ }^{20-23}$ Whether C3 or its activation products play a role in the pathogenesis of sterile inflammation in response to cigarette smoke remains unclear.

In this report, we explored the role of complement $\mathrm{C} 3$ in a mouse model of cigarette smoke-induced emphysema. We show that mice deficient in C3, develop attenuated responses to chronic cigarette smoke exposure characterized by reduced

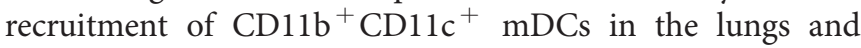
reduced emphysema. We further describe a new proteasedependent pathway for C3a generation in which neutrophil elastase (NE) and, to a lesser degree, matrix metalloproteinase 12 (MMP12), cleave C3 to release C3a. We further show that C3a acts on mDCs to upregulate cell-surface expression of the C3aR. Finally, we confirm the prominent deposition of C3 in the lungs of smokers with emphysema.

\section{RESULTS}

\section{C3 is required for development of smoke-induced emphysema}

Complement is activated in human sera exposed to cigarette smoke; the chemotaxins generated include both $\mathrm{C} 3 \mathrm{a}$ and $\mathrm{C} 5 \mathrm{a} .{ }^{24}$ To evaluate whether activation products of $\mathrm{C} 3$ play a role in the inflammatory response that results in emphysema, we exposed wild-type (WT) and mice deficient in $\mathrm{C} 3\left(\mathrm{C}^{-1-}\right)$ to cigarette smoke or air for 6 months. ${ }^{10,25}$ Hematoxylin and eosin staining of lung sections, micro-computed tomography (microCT) quantification as well as unbiased stereologic morphometry ${ }^{25}$ of the lungs following chronic cigarette smoke exposure showed less lung volume enlargement (emphysema) in $C 3^{-1-}$ as compared with WT mice (Figure 1a, b, $\mathbf{c}$ and Supplementary Figure S1a online).

We found significantly fewer macrophages and neutrophils in the BAL fluid of $\mathrm{C}^{-1-}$ compared with WT mice treated the same way (Figure 1d). Although $M m p 9$ and Mmp12 mRNA expression was increased in the BAL fluid cells of cigarette smoke-exposed WT relative to air-exposed mice, we found significant less induction of these pro-inflammatory genes in smoke-exposed $\mathrm{C}^{-1-}$ mice (Figure 1e, f).
Given the relative B-cell-mediated immune deficiency in $\mathrm{C} 3^{-1-}$ mice, ${ }^{26}$ we examined the possibility that these results could be explained by an occult infection or abnormal immunoglobulin G (IgG) levels. Serial culture of whole-lung homogenates and BAL showed no evidence for bacterial infection in the experimental mice and although serum IgG concentrations were increased in response to smoke, they were not significantly different from those in WT mice (Supplementary Figure S1b).

We have previously shown that exposure to cigarette smoke recruits mDCs marked by high expression of MHC-II, CD11 ${ }^{+}$, and $\mathrm{CD} 11 \mathrm{c}^{+}$into the lung. ${ }^{10}$ In concordance with the reduction in emphysema in smoke-exposed $C 3^{-1-}$ mice, there were fewer mDCs expressing CD11c and CD11b (Figure 1g, h), as well as decreased relative abundance of Th17 cells in the lungs of these mice (Figure 1i). In contrast, we found no significant differences in the relative abundance of IL-17A-producing $\gamma \delta$ T cells (Figure $\mathbf{1 j}$ ).

Expression of IL- 6 and IL-1 $\beta$, two cytokines that are critical for Th17 cell differentiation, ${ }^{27}$ were significantly reduced in BAL fluid cells (e.g., macrophages, neutrophils, lymphocytes, and mDCs) of $\mathrm{C}^{-1-}$ mice exposed to cigarette smoke (Figure 1k-1). BAL fluid cells and isolated lung $\mathrm{CD} 11 \mathrm{c}^{+}$ $\mathrm{CD}_{11 \mathrm{~b}^{+}}$cells recovered from C3-deficient mice exposed to cigarette smoke also showed reduced CD86 expression, a co-stimulatory molecule important for T-cell activation, and C3aR expression (Figure 1m, Supplementary Figure S1c, d). In whole-lung homogenates, we found significantly reduced IL-6 protein and increased TGF- $\beta$ in $C 3^{-1-}$ mice exposed to cigarette smoke (Figure 1n, o). KC concentrations in the BAL fluid of $C 3^{-1-}$ mice exposed to cigarette smoke was also reduced when compared with WT mice (Figure 1p). Together, these findings suggest that $\mathrm{C} 3$ contributes significantly to both the recruitment and activation of immune cells into the lungs of smoke exposed mice and the induction of emphysema.

\section{NE cleaves and activates $\mathrm{C} 3$}

$\mathrm{NE}$, a serine proteinase, has been shown to cleave $\mathrm{C} 3$ protein and generate $\mathrm{C} 3 \mathrm{~d} ;{ }^{28}$ binding of C3d to antigens may enhance antigen presentation and dendritic cell activation thereby facilitating an adaptive immune response to the C3d-linked antigen. ${ }^{29}$ To test the hypothesis that $\mathrm{NE}$ and/or other pro-inflammatory proteinases associated with smoke-induced emphysema can generate activated C3 fragments, we examined the ability of activated recombinant (r)NE, MMP12, and MMP9 to cleave C3 in vitro. We found that $\mathrm{rNE}$ efficiently cleaved purified human plasma C3 and generated in a dose-dependent manner a number of active cleavage products including C3a (Figure 2a) and C3d (Supplementary Figure S2a). Human MMP12 and cathepsin G, but not proteinase 3 , cleaved $\mathrm{C} 3$ and generated $\mathrm{C} 3 \mathrm{a}$ and $\mathrm{C} 3 \mathrm{c}$ fragments (MMP12), albeit less efficiently, when compared with NE (Figure 2b and Supplementary Figure S2b-d). Although MMP9 is also highly upregulated in response to smoke and has been implicated in the pathophysiology of human emphysema, it failed to cleave $\mathrm{C} 3$ even at the highest concentration tested 

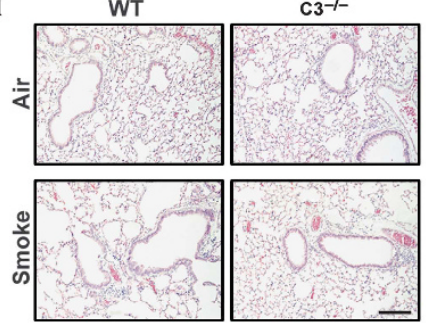

b

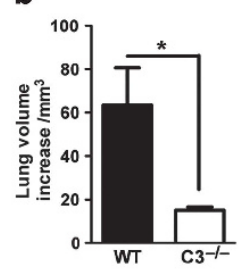

C

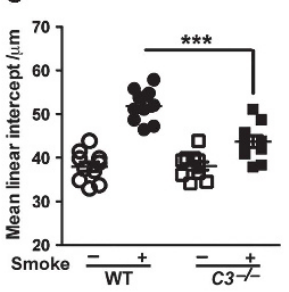

d

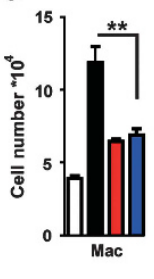

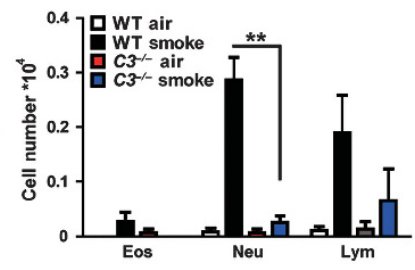

i

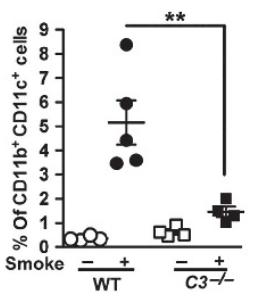

j

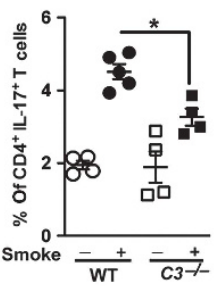

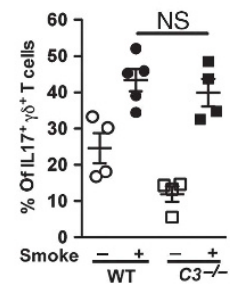
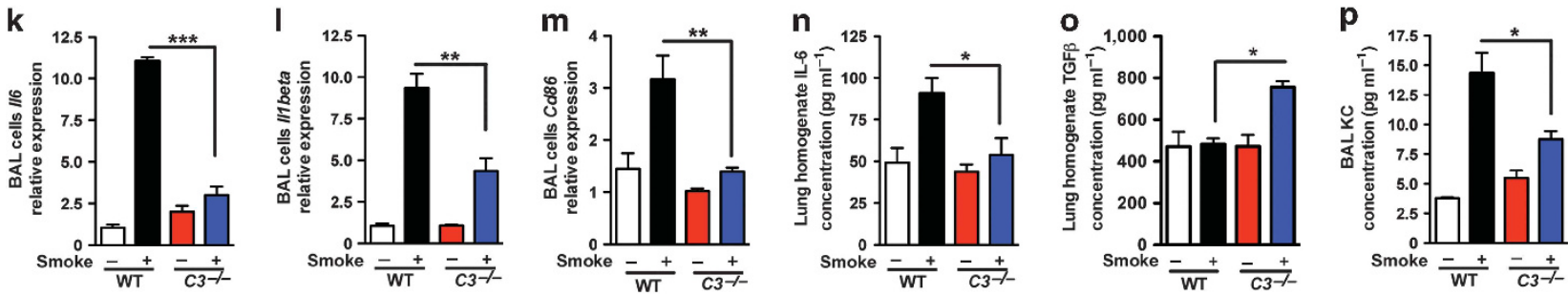

Figure 1 Complement 3 is required in smoke-induced emphysema development. WT or $C 3^{-1-}$ mice were exposed to cigarette smoke or air for 6 months. (a) Representative images of H\&E-stained lung sections from WT and $C 3^{-1}$ mice exposed to air or cigarette smoke. Representative of three independent studies ( $n=4-5$ per group). (b) Micro-CT quantification of lung volume and (c) MLI using unbiased morphometry in the indicated groups of mice $(n=10) .{ }^{*} P<0.05,{ }^{* \star *} P<0.001$, as determined by student $t$ test and one-way ANOVA with Bonferroni's multiple comparison. (d) BAL fluid analyses from the same group of mice ( $n=4$ or 5 per group) showing macrophages (Mac), lymphocytes (Lymph), and neutrophils (Neu). ${ }^{*} P<0.01$, as determined by one-way ANOVA with Bonferroni's multiple comparison. Expression of Mmp9 (e) and (f) Mmp12 mRNA in BAL cells was measured by qPCR. ${ }^{* *} P<0.01$, as determined by the one-way ANOVA with Bonferroni's multiple comparison. (g) Representative and (h) cumulative flow cytometry analysis of $\mathrm{B}_{22} \mathrm{CD}^{-} \mathrm{Cb}^{+} \mathrm{CD} 11 \mathrm{c}^{+} \mathrm{mDCs}$ in the lung of the same group of mice (numbers in each quadrant indicate \% positive cells for the indicated cytokines); right panel cumulative data ( $n=4$ or 5 mice in each group). ${ }^{* *} P<0.01$, as determined by the one-way ANOVA with Bonferroni's comparison. Cumulative intracellular cytokine staining of IL-17A in $\alpha \beta$ (i), and $\gamma \delta$ (j) CD3 ${ }^{+} / \mathrm{CD} 4{ }^{+}$T cells $\left(n=4-5\right.$ in each group). ${ }^{*} P<0.05$, as determined by the one-way ANOVA with Bonferroni's comparison. (k) and (I) Expression of $/ 16$ and $/ 11$ beta mRNA in BAL cells were measured by $\mathrm{qPCR}$. ${ }^{* *} P<0.01,{ }^{* * *} P<0.001$, as determined by the one-way ANOVA with Bonferroni's comparison. $(\mathbf{m})$ Expression of $C d 86 \mathrm{mRNA}$ in BAL cells was measured by $q \mathrm{PCR}$. ${ }^{* *} P<0.01$, as determined by the one-way ANOVA with Bonferroni's multiple comparison. IL-6 concentration (n) and (o) TGF $\beta$ concentration in mouse lung homogenate and (p) KC level in BAL fluid was measured by multiplex assay and ELISA (TGF $\beta$ ). ${ }^{*} P<0.05$, as determined by the one-way ANOVA with Bonferroni's comparison. All mRNA gene expression was normalized to $18 \mathrm{~S}$ expression and analyzed by $\Delta \Delta C t$ method. Results are represented as mean $\pm \mathrm{s}$.e.m. from three independent experiments with 4-5 mice in each group. ANOVA, analysis of variance; H\&E, hematoxylin and eosin; mDCs, myeloid dendritic cells; micro-CT, micro-computed tomography; MLI, mean linear intercept; qPCR, quantitative reverse transcription PCR; IL, interleukin; WT, wild type. Scale bar: $100 \mu \mathrm{m}$.

$(10 \mu \mathrm{g} / \mathrm{ml}$; Supplementary Figure S2b) indicating some serine proteinases (e.g., NE, cathepsin G) and metalloproteinases (e.g., MMP12) can cleave $\mathrm{C} 3$ to generate several active fragments (e.g., C3a, C3c, and C3d).

To evaluate the functional significance of cleaved C3 fragments, we examined in vitro the migration of human and mouse mDCs in response to NE- or MMP12-mediated cleavage of purified fragments of C3. Both mouse bonemarrow-derived dendritic cells (BMDCs) (Figure 2c) and human monocyte-derived dendritic cells (Figure 2d) migrated in response to NE-cleaved, but not to MMP12-cleaved, C3 fragments suggesting that the efficient cleavage of C3 by NE likely plays a more important role in mDCs recruitment into the lungs.

\section{C3a autocrine/paracrine responses increase C3a receptor (C3aR) expression}

Given the importance of $\mathrm{C} 3$ in emphysema development and recruitment of lung mDCs, we next asked whether activated C3 fragments generated by NE and MMP12 could stimulate the expression of the $\mathrm{C} 3 \mathrm{a}$ receptor. To address this question, we measured the expression of C3arl mRNA in BAL fluid inflammatory cells. We have previously shown an increase

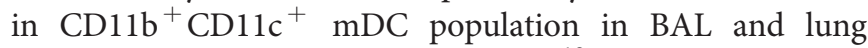
parenchyma of mice exposed to smoke. ${ }^{10}$ Similarly, we found

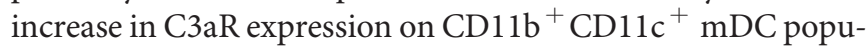
lation in BAL of WT mice exposed to smoke (Supplementary Figure S3). Consistently, WT but not $C 3^{-1-}$ BAL cells showed a fivefold increase in C3ar1 mRNA expression in response to 
a
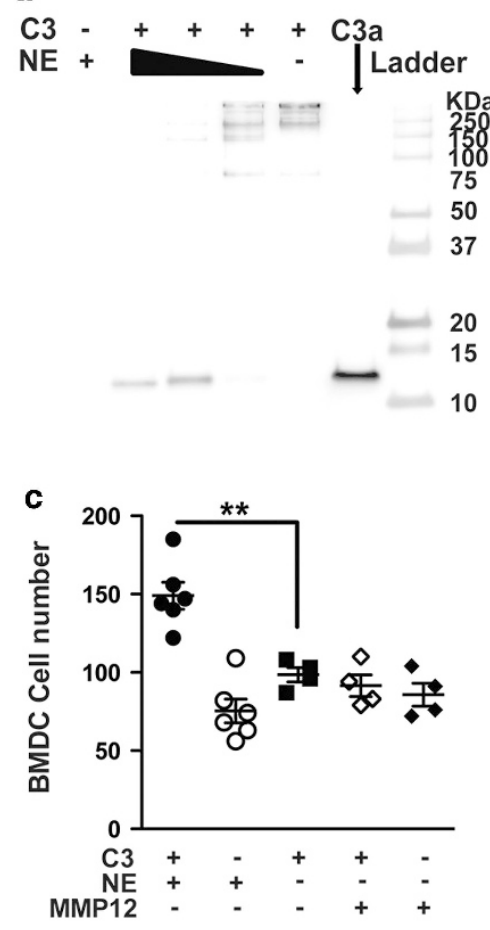

b

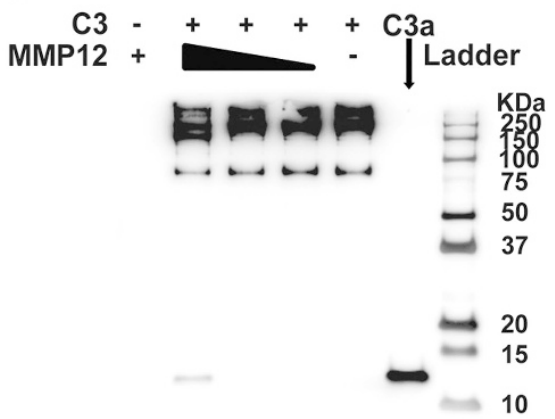

d

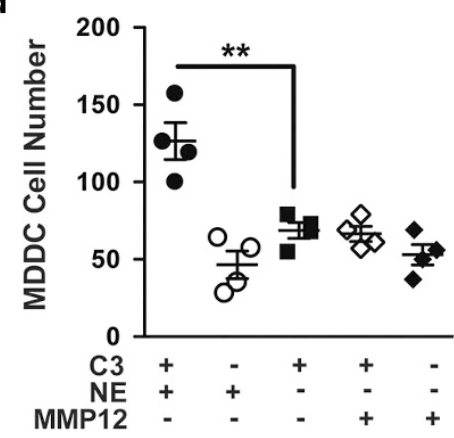

Figure 2 NE and MMP12 cleave and activate complement C3. Purified human C3 $(100 \mu \mathrm{g} / \mathrm{ml})$ was cleaved with different concentrations of human (a) NE $(10 \mu \mathrm{g} / \mathrm{ml}, 1 \mu \mathrm{g} / \mathrm{ml}, 0.1 \mu \mathrm{g} / \mathrm{ml})$ and (b) MMP12 $(10 \mu \mathrm{g} / \mathrm{ml}, 1 \mu \mathrm{g} / \mathrm{ml}, 0.1 \mu \mathrm{g} / \mathrm{ml})$ for $4 \mathrm{~h}$ at $37^{\circ} \mathrm{C}$. Cleavage products were separated using $10 \%$ non-reducing Tricine gels, and detected by western blot using anti-C3a antibody; purified C3a, NE, and MMP12 were loaded as controls. (c) BMDCs $\left(5 \times 10^{4}\right)$ and $(\mathrm{d})$ MDDCs $\left(5 \times 10^{4}\right)$ were suspended in media (RPMI-1640) and were placed on 48-well chemotaxis chambers for $1 \mathrm{~h}$ in the presence of intact or MMP12, NE-cleaved C3 protein; control conditions included NE and MMP12. Transmigrating cells were detected in stained membranes visualized under microscope (original magnification $\times 20$ ) and reported as the average number of cells/field $(n=4-6)$. ${ }^{* \star} P<0.01$ as determined by one-way ANOVA with Bonferroni's multiple comparison. Results are represented as mean \pm s.e.m. from three independent experiments. ANOVA, analysis of variance; BMDCs, bone marrow-derived dendritic cells; MDDCs, myeloid-derived dendritic cells; MMP, matrix metalloproteinase; $\mathrm{NE}$, neutrophil elastase.

cigarette smoke (Figure 3a). In agreement with the mRNA data, flow cytometry of CD11c ${ }^{+}$lung APCs and immunofluorescent staining of lung tissue in mice exposed to smoke showed increased $\mathrm{C} 3 \mathrm{aR}$ protein expression in WT compared with $C 3^{-/-}$mice treated in the same manner (Figure 3b-d). We next examined the direct activation of $\mathrm{C} 3 \mathrm{aR}$ in mouse BMDCs. BMDCs stimulated with C3aR agonist (CAS 94499760-8) significantly increased the expression of C3ar1, as well as pro-inflammatory genes including $I l 6, M m p 9$, and $M m p 12$ (Figure $3 \mathbf{e}-\mathbf{h})$. As the only difference between WT and $C 3^{-1-}$ mice is the inability to produce $\mathrm{C} 3$ in the latter, these results strongly suggest that the upregulation of $\mathrm{C} 3 \mathrm{aR}$ in the former is a consequence of the stimulation provided by $\mathrm{C} 3 \mathrm{a}$, some other $\mathrm{C} 3$ breakdown product, or another complement activation fragment downstream of C3 produced during exposure to cigarette smoke. Consistent with this hypothesis, we found that $\mathrm{CD} \mathrm{a}^{+}$mDCs, isolated from lung tissue of active or former smokers irrespective of emphysema significantly increased $\mathrm{C} 3 \mathrm{aR}$ expression in response to $\mathrm{C} 3 \mathrm{a}$ stimulation (Figure $\mathbf{3} \mathbf{i}$ and Supplementary Figure S4a, b). Together, our findings confirm an autocrine/paracrine $\mathrm{C} 3 \mathrm{a} / \mathrm{C} 3 \mathrm{aR}$ axis in humans and in mice.

\section{Attenuated chemotactic responses to cigarette smoke in C3aR deficiency}

We have previously shown that $\mathrm{CD} 11 \mathrm{c}^{+}$mDCs are recruited into the lungs of mice exposed to chronic smoke. Given the robust $\mathrm{C} 3$-dependent increase in $\mathrm{C} 3 \mathrm{aR}$ expression, we next examined whether direct activation of the $\mathrm{C} 3 \mathrm{aR}$ could promote recruitment of lung mDCs. As expected, a C3aR agonist (CAS 944997-60-8) significantly increased the migration of WT BMDCs when compared with vehicle control (Figure 4a). We found that BAL fluid from WT mice exposed to chronic smoke also resulted in significantly enhanced BMDC migration, when compared with the BAL fluid obtained from $C 3^{-1-}$ mice treated the same way (Figure 4b). We next tested the kinetics of $\mathrm{C} 3 \mathrm{aR}$-mediated migration by measuring BMDC chemotaxis towards BAL fluid over $1 \mathrm{~h}$. We found that although the migration of BMDCs lacking C3aR increased over time toward chemotaxins in BAL fluid from WT mice exposed to cigarette smoke, the response was significantly less than that of BMDCs isolated from WT mice (Figure 4c). Together these data suggest that the $\mathrm{C} 3 \mathrm{aR}$ plays a critical role in the migration of $\mathrm{DC}$ to the lung in response to cigarette smoke. 


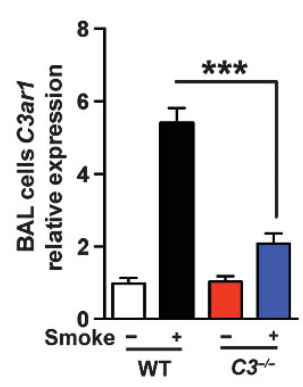

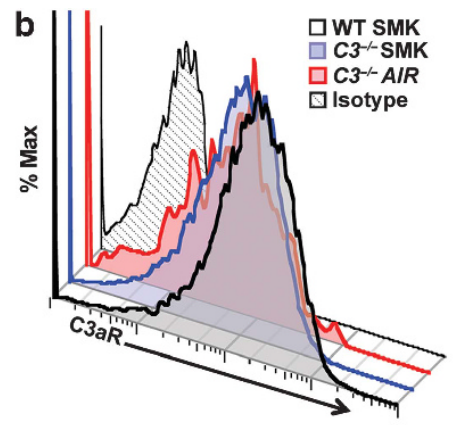

c

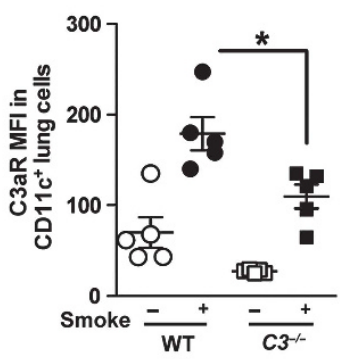

d

Air

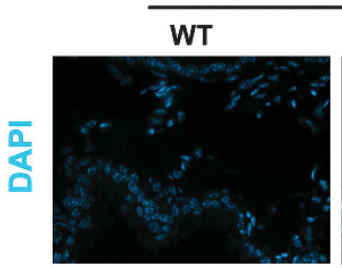

$\mathrm{C}^{-/-}$
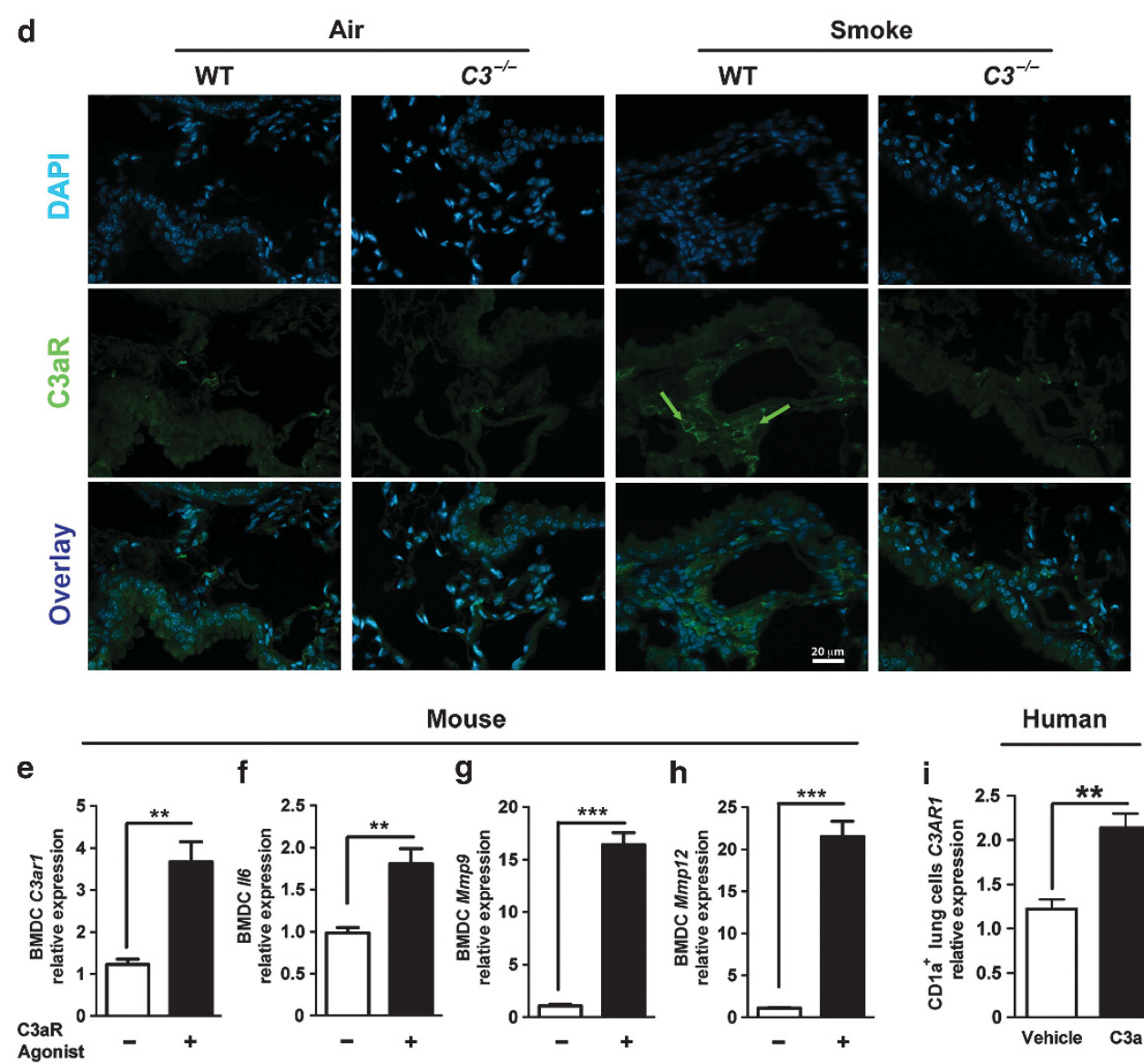

Mouse

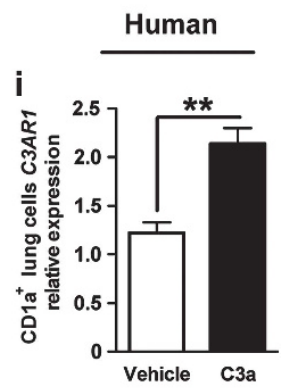

Figure 3 Expression of $\mathrm{C} 3 a \mathrm{R}$ in mouse lung inflammatory cells and human mDCs. WT and C3-deficient mice were exposed to cigarette smoke or air for 6 months. (a) Expression of C3ar1 mRNA in BAL cells isolated from WT or $C 3^{-1}$ mice exposed to air or cigarette smoke was measured by qPCR. ${ }^{* * *} P<0.001$ as determined by the one-way ANOVA with Bonferroni's multiple comparison. Representative (b) and cumulative data (c) measuring C3aR $\mathrm{MFI}$ in single lung cells gated on $\mathrm{B}_{22}{ }^{-} \mathrm{CD} 11 \mathrm{c}^{+}$population using flow cytometry. ${ }^{*} P<0.05$ as determined by the one-way ANOVA with Bonferroni's multiple comparison. (d) Representative photomicrograph of WT and $C 3^{-1-}$ mouse lung tissue exposed to 6 months of smoke or air immunostained for expression of C3aR (green) or nuclei (blue; DAPI). Green arrows indicate C3aR ${ }^{+}$cells. (e) to (h) Mouse BMDCs $\left(2 \times 10^{5}\right)$ were treated with C3aR agonist (CAS $944997-60-8 ; 20 \mathrm{ng} / \mathrm{ml}$ ) or vehicle (2\% DMSO) for $48 \mathrm{~h}$. Expression level of C3aR1, II6, Mmp9, and Mmp12 mRNA were measured using qPCR ( $n=4$ in each group; ${ }^{* \star} P<0.01$ and ${ }^{\star * \star} P<0.001$ as determined by student $t$ test). (i) Human CD1a ${ }^{+}$lung mDCs $\left(2 \times 10^{5}\right)$ were treated with purified human C3a $(40 \mathrm{ng} / \mathrm{ml})$ for $24 \mathrm{~h}$ or vehicle (media). Expression level of $C 3 A R 1 \mathrm{mRNA}$ was measured by qPCR. $n=3 ;{ }^{* \star} P<0.01$ as determined by student $t$ test. All gene expressions were normalized to $18 \mathrm{~S}$ ribosomal RNA expression and analyzed by $\triangle \Delta C t$. Results are represented as mean $\pm \mathrm{s}$.e.m. from three independent experiments with 4-5 mice in each group (a-d). ANOVA, analysis of variance; BMDCs, bone marrow-derived dendritic cells; C3, complement protein 3; C3aR, C3a receptor; DAPI, 4',6-diamidino-2-phenylindole; DMSO, dimethyl sulfoxide; mDCs, myeloid dendritic cells; MFI, mean fluorescent intensity; qPCR, quantitative reverse transcription PCR; WT, wild type. Scale bar: $20 \mu \mathrm{m}$.

C3aR signaling is critical in smoke-induced emphysema We next examined the contribution of the C3aR in smokeinduced emphysema. $\mathrm{C}_{\mathrm{ar}}{ }^{-1-}$ mice exposed to chronic cigarette smoke had less emphysema, as measured by quantitative
microCT, hematoxylin and eosin staining of lung sections, unbiased stereologic morphometry of lung volumes as compared with WT mice exposed to cigarette smoke (Figure 5a, b). We found no differences in total number of lymphocytes or 

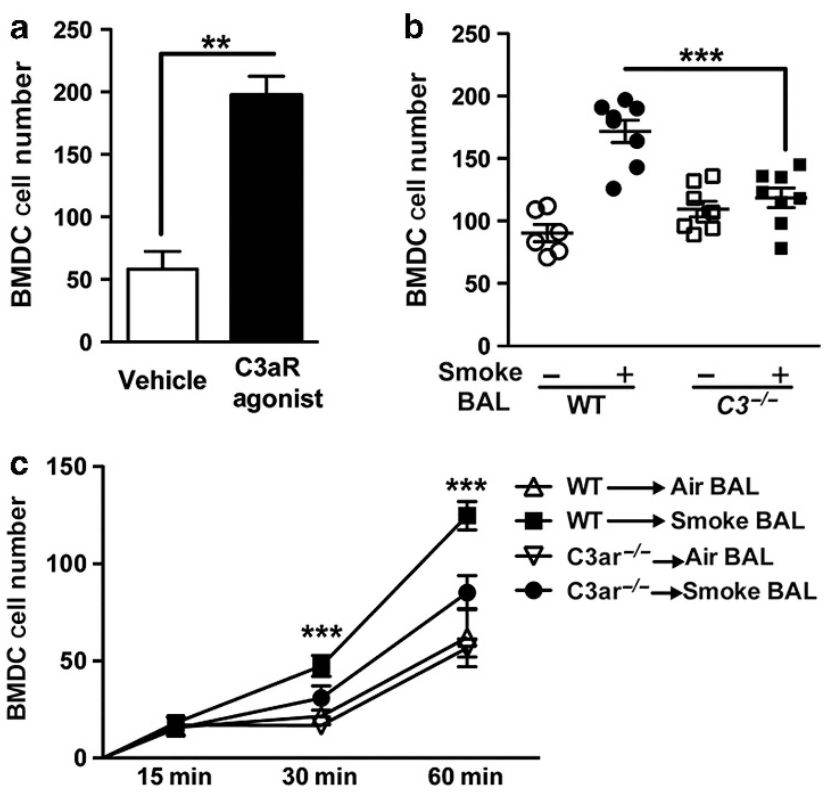

Figure $4 \mathrm{C} 3 \mathrm{aR}$ is required for efficient chemotaxis. (a) BMDCs $\left(5 \times 10^{4}\right)$ from WT mice were suspended in media (RPMI-1640) and were placed on 48-well chemotaxis chambers. After $1 \mathrm{~h}$ of incubation with C3aR agonist (CAS 944997-60-8; $100 \mathrm{ng} / \mathrm{ml}$ ) or vehicle (RPMl-1640) transmigrating BMDCs were detected in stained membranes, visualized under microscope and reported as the average number of cells per field. ${ }^{* \star} P<0.01$ as determined by the student $t$ test. (b) BMDCs $\left(5 \times 10^{4}\right)$ from WT mice were placed on 48-well chemotaxis chambers. After $1 \mathrm{~h}$ of incubation with BAL fluid supernatant pooled from WT or $C 3^{-1-}$ mice exposed to 6 months of air or smoke, transmigrating BMDCs were detected in stained membranes and were visualized under microscope and reported as the average number of cells per field. ${ }^{\star \star \star} P<0.001$ as determined by one-way ANOVA test with Bonferroni's multiple comparison. (c) BMDCs $\left(5 \times 10^{4}\right)$ from WT and $\mathrm{C}_{3} \mathrm{ar}^{-1-}$ mice were placed on 48-well chemotaxis chambers. After 15-, 30- and 60 min of incubation with BAL fluid supernatant pooled from WT mice exposed to 6 month of air or smoke, transmigrating BMDCs were detected in stained membranes, visualized under microscope and reported as the average number of cells per field. ${ }^{* * *} P<0.001$ as determined by one-way ANOVA test with Bonferroni's multiple comparison. Results are represented as mean \pm s.e.m. from three independent experiments $(n=6-8)$. ANOVA, analysis of variance; BMDCs, bone marrow-derived dendritic cells; C3, complement protein 3; C3aR, C3a receptor; WT, wild type.

macrophages that we recovered in the BAL fluid, but neutrophil recovery was significantly less in BAL fluid of $\mathrm{C}_{3} \mathrm{ar}^{-1-}$ mice as compared with WT mice (Figure 5c). Similar to our findings in $\mathrm{C} 3^{-1-}$ mice, the quantity of mRNA specific for $\mathrm{Mmp} 9$ and Mmp12 obtained from BAL fluid cells in $\mathrm{C}_{3} \mathrm{rr}^{-1-}$ mice was significantly lower when compared with WT mice treated the same way (Figure 5d, e). Flow cytometry analysis of single cells isolated from whole lungs of mice showed a significant decrease in the relative abundance of $\mathrm{CD} 11 \mathrm{~b}^{+} \mathrm{CD} 11 \mathrm{c}^{+}$mDCs in ${\mathrm{C} 3 a r^{-1-}}^{-}$as compared with WT mice, both exposed to smoke (Figure 5f). Interestingly, the relative abundance of mDCs in whole lungs of $\mathrm{C}_{3 a r^{-1-}}$ mice exposed to smoke was not significantly different from control mice exposed to air (Figure 5g).

We detected a large of number of IL-17A-producing cells in naïve $C 3 a r^{-1-}$ mice; the numbers of these cells paradoxically rose when these mice were exposed to cigarette smoke (Figure 5h). This increase in IL-17A-producing cells was accompanied by a comparable increase in $\gamma \delta$ T cells expressing IL-17 (Figure 5h, i), raising the possibility that signaling through $\mathrm{C} 3 \mathrm{aR}$ negatively regulates this cell population which we previously showed plays a protective role in smoke-induced emphysema. ${ }^{10}$ Quantitative RT-PCR revealed that the mRNA level of IL6 and IL1 $\beta$ in BAL fluid cells were reduced in C3ar ${ }^{-1-}$ mice exposed to cigarette smoke when compared with WT counterparts, consistent with what was observed $C 3^{-1-}$ mice (Figure 5j, k). Congruently, there was no increase in CD86 mRNA in BAL cells of the smoke exposed $\mathrm{C}_{3} \mathrm{ar}^{-1-}$ mice (Figure 51). We next examined the function of $\mathrm{CD}_{11 \mathrm{c}^{+}}$ $\mathrm{CD}_{11 \mathrm{~b}^{+}}$lung mDCs isolated from WT, $\mathrm{C}^{-1-}$, and $\mathrm{C} 3 \mathrm{ar}^{-1-}$ mice exposed to air or smoke. As expected, lung mDCs isolated from the lungs of WT exposed to smoke express IL-6 (Figure 5m) and when co-cultured with naïve CD4 T cells induced the production of IL-6 and IL-17 cytokines (Figure 5n). In contrast, $\mathrm{CD}_{11 \mathrm{c}^{+}} \mathrm{CD}_{11 \mathrm{~b}^{+}}$lung mDCs isolated from $\mathrm{C3}^{-1-}$ and $\mathrm{C}_{3} \mathrm{ar}^{-1-}$ failed to express IL-6 (Figure 5m) or drive naïve $\mathrm{T}$ cells to express the same cytokine (Figure 5n), suggesting that the $\mathrm{mDCs}$ from the $\mathrm{C} 3$-deficient mice are significantly less activated. These functional data provide further evidence that C3a-mediated signaling through the $\mathrm{C} 3 \mathrm{aR}$ is necessary for the development of an inflammatory response to cigarette smoke that among other proinflammatory effects, involves the recruitment of $\mathrm{CD} 11 \mathrm{~b}^{+}$ CD11 $\mathrm{c}^{+}$mDCs to the lung that drive Th17 cell differentiation and emphysema.

\section{Increased lung deposition and plasma concentrations of C3 in smokers with emphysema}

We next reasoned that if these same mechanisms were operative in humans with emphysema, we should expect to find abundant deposits of C3 and its fragments in lungs of smokers with emphysema. Immunohistological studies showed deposition of $\mathrm{C} 3$ in the airways and vascular endothelial cell of lungs removed from former smokers with emphysema, but not in those without emphysema (Figure 6a). Furthermore, extensive analysis of human surgical lung tissue failed to show any evidence for bacterial pathogens, indicating that these deposits developed in the absence of acute infection (data not shown). Lung tissue from mice exposed to cigarette smoke likewise showed airway deposits of C3 (Figure 6b).

Quantification of C3 concentration in the plasma of a well-characterized cohort of smokers showed a significant increase in $\mathrm{C} 3$ in the smokers with emphysema, and was independent of active exposure to smoke (Figure 6c, Supplementary Figure S4c, d). The plasma C3 concentration also negatively correlated with the extent of airway obstruction as determined by the decreased ratio of forced expiratory volume in one second (FEV1) and forced vital capacity, but not with different stages of chronic obstructive pulmonary disease (Figure 6d, Supplementary Figure S4e). In contrast, plasma C3a concentration in smokers with or without emphysema showed no significant differences, or correlation with airway 
obstruction (e.g., FEV1/forced vital capacity) (Supplementary Figure S4f, g). The relatively rapid turnover of C3 during inflammation prompted us to search for a possible reduction in C3 clearance as a plausible mechanism for its increase plasma concentration and deposition in the lung tissue of smokers with emphysema. However, flow cytometry evaluation of lung mDCs in smokers with and without emphysema failed to show a significant difference in the expressional pattern of complement protein receptors such as CD46, CD55, CD95, or CD97 (Supplementary Figure S5).

\section{DISCUSSION}

Indirect evidence suggests that smoking-induced activation and/or consumption of complement is associated with the
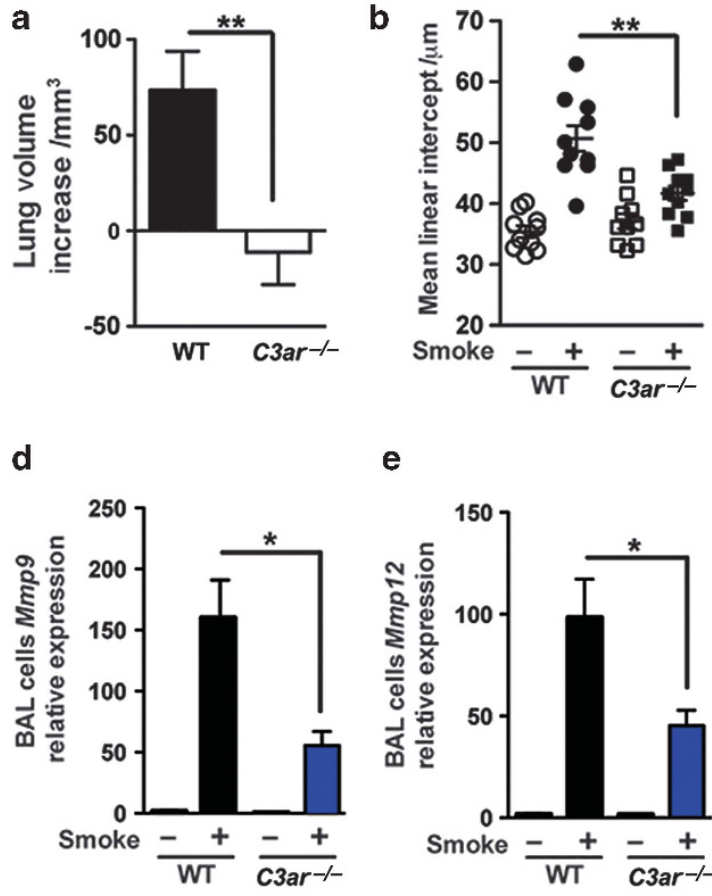

e

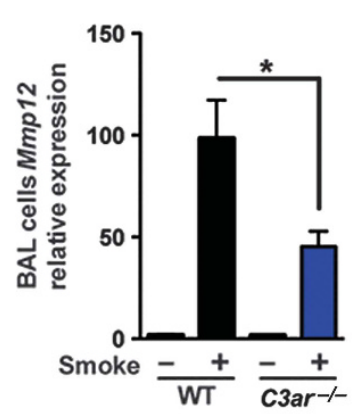

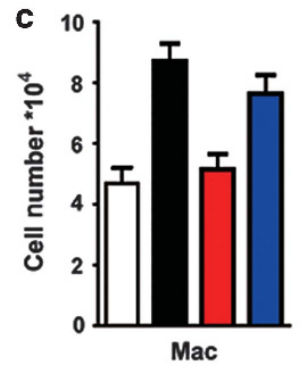

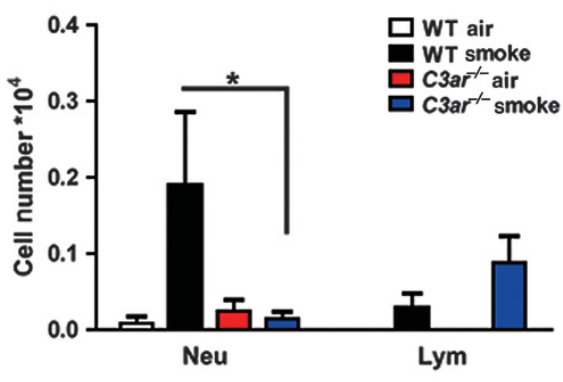

f

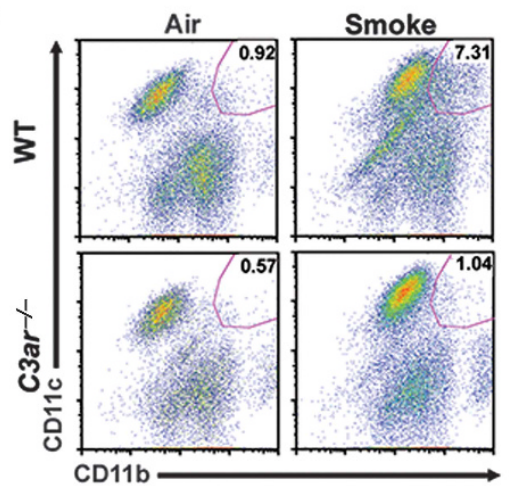

g

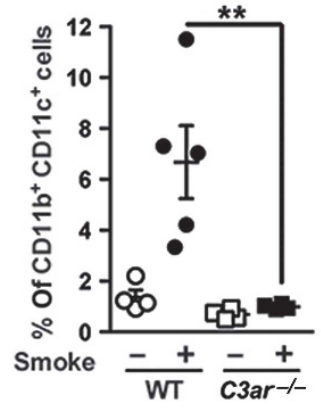

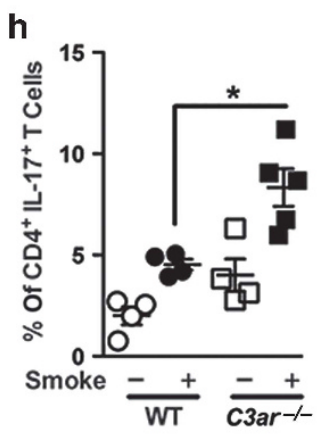
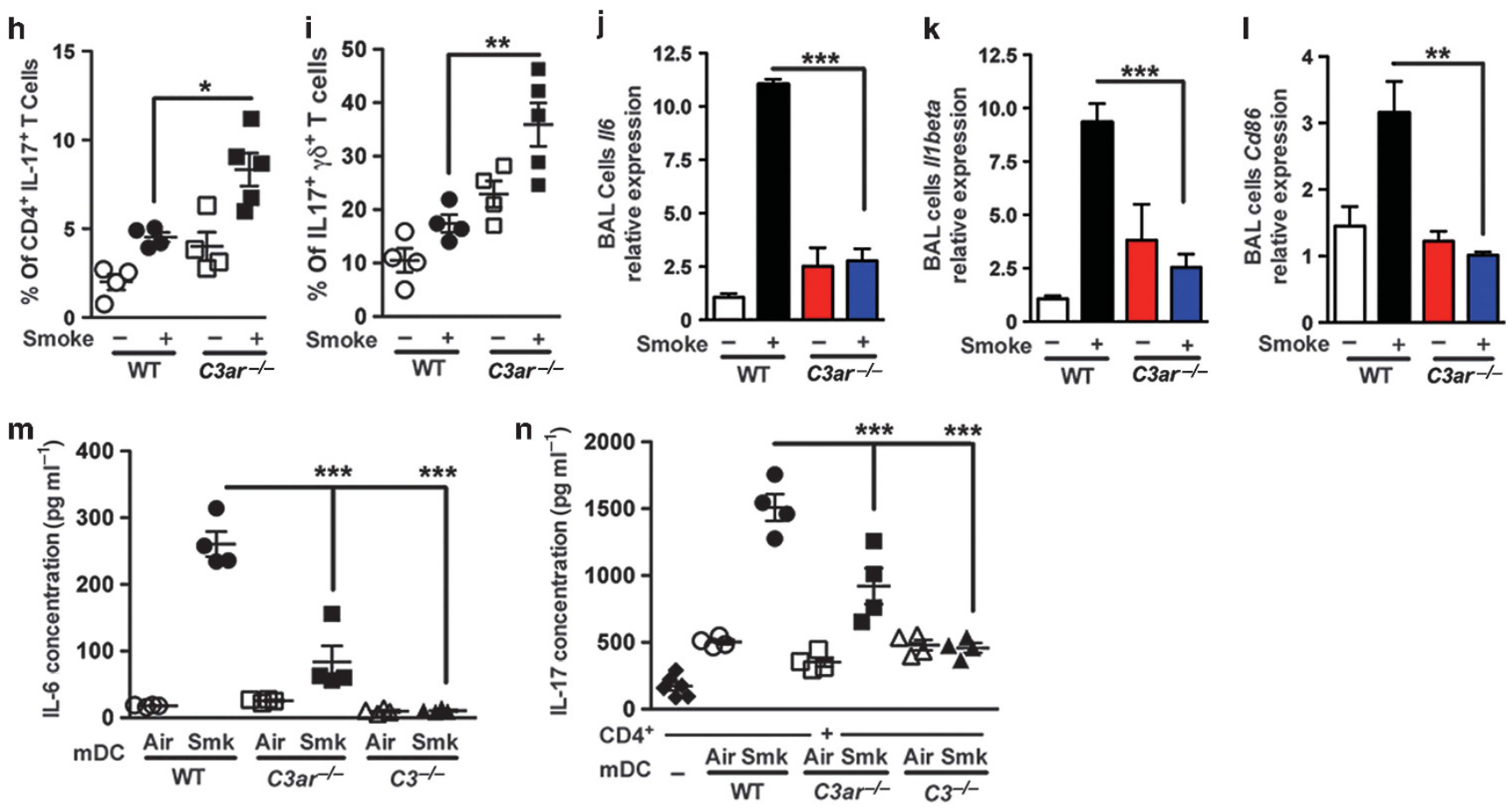
development of emphysema. ${ }^{24,30,31}$ The current report links these observations mechanistically at the molecular level and demonstrates for the first time how complement-derived C3a provides a means by which inflammatory cells may be recruited into lung parenchyma, and mDCs are activated following exposure to cigarette smoke. We show that in contrast to lung

a Human
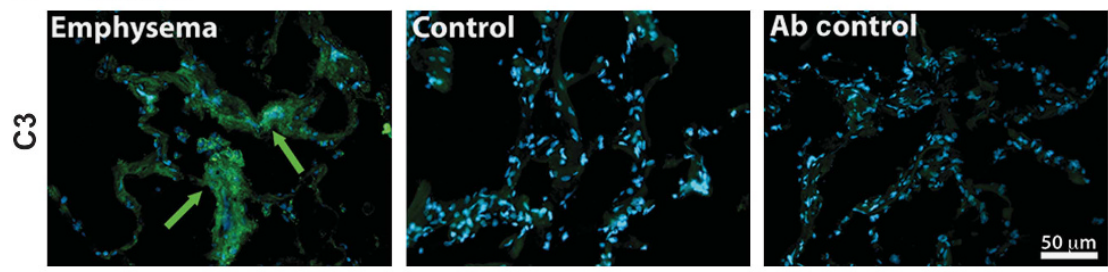

b Mouse
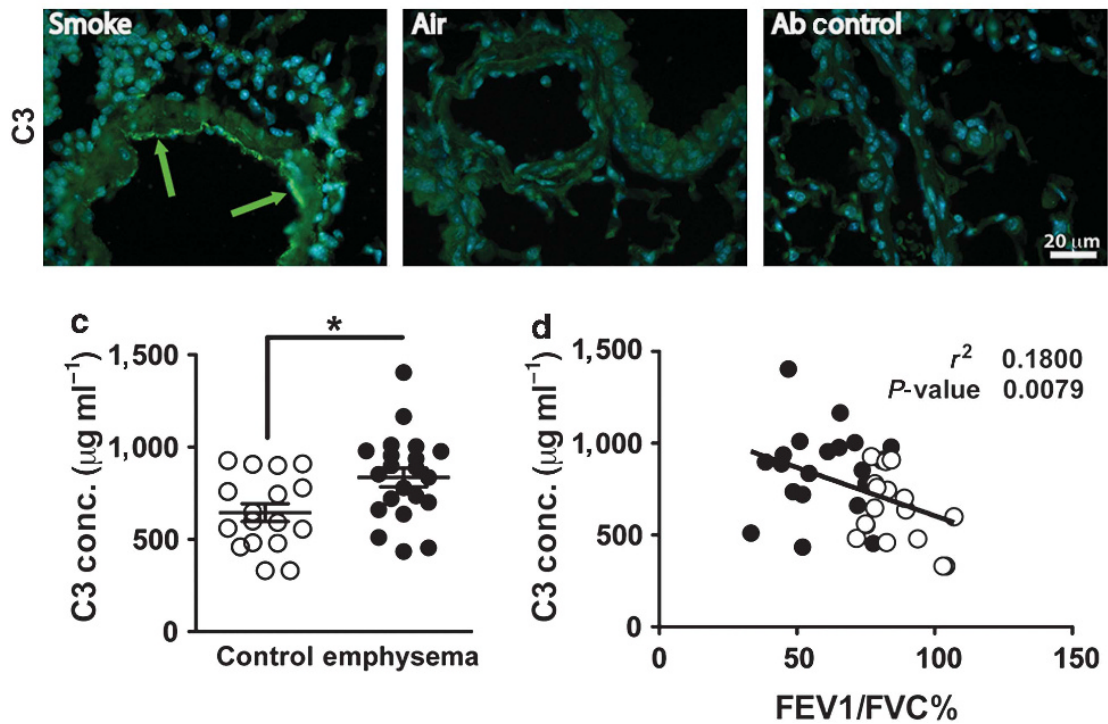

Figure 6 Detection of complement 3 in human and mouse emphysematous lungs. (a) Representative fresh frozen lung tissue obtained from emphysema or control subjects were stained with anti-C3 or non-immune control antibodies (far right panel). Green fluorescence was achieved by Alexa Fluor 488 (AF488)-conjugated secondary antibody and blue fluorescence indicated DAPI nucleus staining. Figures show overlay of green and blue fluorescence. Scale bar: $50 \mu \mathrm{m}$. Green arrows indicate C3 deposition. (b) Representative paraffin-embedded lung tissue from mice exposed to 6 months of cigarette smoke or air that were stained with anti-C3 or non-immune control antibodies (far right panel). Green fluorescence was achieved with AF488conjugated secondary antibody and blue fluorescence resulted from DAPI nucleus staining. Figure shows overlay of green and blue fluorescence. Scale bar: $20 \mu \mathrm{m}$. Green arrows indicate C3 deposition. (c) Plasma from control $(n=18)$ and emphysema patients $(n=22)$ were used in an ELISA to measure C3 concentration. ${ }^{* \star} P<0.01$ as determined by the Student $t$ test. (d) Correlation of plasma C3 concentration compared with FEV1/FVC\%. Solid dots represent individual patients with emphysema and open dots represent individual control patients. $P$ value and $r^{2}$ were obtained by linear regression model. Results are represented as mean \pm s.e.m. ANOVA, analysis of variance; BMDCs, bone marrow-derived dendritic cells; C3, complement protein 3; DAPI, 4',6-diamidino-2-phenylindole; FVC, forced vital capacity.

Figure $5 \mathrm{C} 3 \mathrm{aR}$ is critical in cigarette smoke-induced emphysema. WT and C3ar ${ }^{-1-}$ mice were exposed to cigarette smoke or air for 6 months. (a) Micro-CT quantification of lung volume in indicated groups of mice, and (b) MLI was measured using unbiased morphometry in the same groups of mice $(n=10) .{ }^{* *} P<0.01$ as determined by the student $t$ test and one-way ANOVA with Bonferroni's multiple comparison. (c) BAL fluid analyses from the same group of mice ( $n=4$ or 5 per group) showing macrophages (Mac), lymphocytes (Lymph), and neutrophils (Neu). ${ }^{*}<0.05$ as determined by the student $t$ test. (d) Expression of Mmp9 and (e) Mmp12mRNA in BAL cells was measured by qPCR. ${ }^{* \star} P<0.01$ as determined by one-way ANOVA with Bonferroni's multiple comparison. (f) Representatives and (g) cumulative of flow cytometry analysis of $\mathrm{B}_{22} \mathrm{C}^{-} \mathrm{CD}_{11 \mathrm{~b}}{ }^{+} \mathrm{CD} 11 \mathrm{c}^{+}$mDCs (enclosed population) in the lung of the same groups of mice ( $n=4$ or 5 mice in each group). ${ }^{* *} P<0.01$ as determined by one-way ANOVA with Bonferroni's multiple comparison. Cumulative intracellular cytokine staining of IL-17A in $\alpha \beta(\mathbf{h})$, and $\gamma \delta \mathrm{CD} 3^{+} / \mathrm{CD} 4^{+}$T cells (i) $(n=4$ or 5 in each group). Numbers in each quadrant indicate $\%$ positive cells for the indicated cytokines. ${ }^{*} P<0.05$ as determined by one-way ANOVA with Bonferroni's multiple comparison. (j) Expression of II6 and (k) I/1 beta mRNA in BAL cells were measured by qPCR. ${ }^{* \star \star} P<0.001$ as determined by one-way ANOVA test with Bonferroni's multiple comparison. (I) Expression of $C d 86$ mRNA in BAL cells was measured by qPCR. ${ }^{\star \star} P<0.01$ as determined by one-way ANOVA with Bonferroni's multiple comparison. (m) $\mathrm{CD}_{11 \mathrm{c}^{+}} \mathrm{mDCs}\left(2 \times 10^{4}\right)$ isolated from whole lung homogenates isolated from WT, $C 3 a r^{-1-}$, and $C 3^{-1-}$ mice exposed to 6 months of air or smoke, were cultured in complete media for 3 days, and the concentration of IL 6 in the supernatant was measured by multiplex assay. ${ }^{\star * \star} P<0.001$ as determined by one-way ANOVA test with Bonferroni's multiple comparison. (n) CD4 ${ }^{+}$splenic T cells isolated from naïve WT mice were co-cultured with CD11c ${ }^{+}$ mDCs shown in $(\mathbf{m})$ in 10:1 ratio (CD4 ${ }^{+} \mathrm{T}$ cells and CD11 ${ }^{+}$mDCs) for 3 days, and the concentration of IL17 in the supernatant was measured by multiplex assay. CD4 ${ }^{+}$T cells $\left(2 \times 10^{5}\right)$ without CD11 ${ }^{+} \mathrm{mDCs}$ was cultured for 3 days as control. ${ }^{* \star} P<0.001$ as determined by one-way ANOVA test with Bonferroni's multiple comparison. All mRNA gene expression was normalized to $18 \mathrm{~S}$ ribosomal RNA expression and analyzed by $\triangle \Delta C t$ method. Results are expressed as mean \pm s.e.m. from three independent experiments with 4-5 mice in each group. ANOVA, analysis of variance; BMDCs, bone marrow-derived dendritic cells; C3, complement protein 3; C3aR, C3a receptor; IL, interleukin; MFI, mean fluorescent intensity; mDCs, myeloid dendritic cells; micro-CT, micro-computed tomography; MLI, mean linear intercept; qPCR, quantitative reverse transcription PCR; WT, wild type. 
mDCs isolated from WT exposed to chronic smoke, those from $C 3^{-1-}$ and $C 3 a r^{-1-}$ mice fail to strongly induce IL-6 and IL-17 production in CD4 $\mathrm{T}$ cells. Together, these findings indicate that $\mathrm{C} 3$ acts as an upstream mediator in cigarette smoke-induced model of emphysema.

We show that the chemotactic anaphylatoxin, C3a, could be released from complement C3 in the presence of activated serine proteinase (e.g., NE, cathepsin G, etc.) and to a lesser extent, MMP12 that are prominently present in innate lung immune cells (neutrophils and macrophages). The interaction of complement and the infiltrating innate immune cells could create a positive feedback loop that results in C3a-mediated autocrine or paracrine signaling that upregulates C3aR expression. Specifically, we show that C3a signaling upregulates $\mathrm{C} 3 \mathrm{aR}$ on the surface of $\mathrm{mDCs}$, rendering them more responsive to $\mathrm{C} 3 \mathrm{a}$ in the lungs, whereas mice lacking $\mathrm{C} 3 \mathrm{aR}$ have reduced expression of CD86 when exposed to smoke.

Our in vivo data support a significant role for the generation of $\mathrm{C} 3 \mathrm{a}$ that is upstream of the acquired immune responses to lung tissue elements found in end-stage emphysematous lungs of humans and in animal models of emphysema. The clinical significance of C3 activation in smoke-induced emphysema was further underscored by our findings that C3 fragments deposit on the lung tissue of smokers with emphysema. Similarly, we detected C3 fragments on the lung vascular endothelial cell in mice exposed to chronic smoke, a finding that has not been previously appreciated, but may be of significant importance given the strong association between smoking and vascular diseases in humans. ${ }^{32,33}$ Although these findings merit further examination of the spatiotemporal regulation of $\mathrm{C} 3$ activation in response to smoke, further dissection of their effect on vascular endothelial cells are beyond the scope of the current report.

Several complement proteins are acute phase reactants, including C3; consequently, although measurements of plasma complement levels are often elevated in the face of a prolonged inflammatory stimulus, they can also be depressed when sampling occurs before the acute phase response has started or if the disease causes such extensive catabolism that synthesis of new protein is not able to restore homeostasis. Although, previous studies have reported no change or a reduction in C3 serum concentration of smokers with chronic obstructive pulmonary disease, ${ }^{30,31}$ here, we found a significant increase in plasma levels of C3 that correlated with disease severity, but not with current smoking status. Furthermore, our data provide new insights into how C3a, cleaved from C3 by elastolytic proteinases (e.g., NE and MMP12), could drive a positive feedback loop that stimulates inflammation in lungs exposed to cigarette smoke.

Animal models of acute and chronic cigarette smokeinduced lung disease share similar characteristics with the innate and acquired inflammatory changes seen in the lungs of human smokers. ${ }^{34}$ Specifically, an acute 3-day exposure to cigarette smoke results in sterile inflammation and activate the inflammasome pathways that facilitate recruitment of neutrophils, followed by macrophages, ${ }^{35}$ in the lungs. This finding was first described in humans. ${ }^{1}$ In contrast, we have shown that chronic smoke exposure results in a sterile inflammation that activates mDCs and induces a Th17 inflammatory response that results in autoimmune-mediated destruction of the lungs. ${ }^{4}$ In this study, we show that activation of $\mathrm{mDCs}$ as determined by increased expression of co-stimulatory molecules such as CD86, results from autocrine/ paracrine signaling by $\mathrm{C} 3 \mathrm{a}$ that stimulates $\mathrm{C} 3 \mathrm{aR}$ expression and efficient induction of pro-inflammatory cytokines (e.g., IL-17 and IL-6). These findings provide a new insight into the link between innate immune activation of $\mathrm{C} 3$ molecule and smokeinduced sterile inflammation that could propagate autoimmune inflammation and Th17 responses. ${ }^{9,12}$

C3 plays a critical role in innate immune system activation, a task that is most often associated with protection against pathogenic insults. $^{36}$ C3 deficiency is associated with increased susceptibility to bacterial infection both in mice and humans. ${ }^{37-39}$ Given the long duration (6 months) of smoke exposure in our mice, we routinely monitored for occult bacterial infection. We found a slightly increased rate of bacterial infection in $C 3^{-1-}$ mice (8/42) compared with WT (1/57) or C3ar ${ }^{-/-}$mice (1/41) irrespective of smoke exposure. We did not include mice with spontaneous pneumonia in our data analyses. It is interesting to note nevertheless that despite increased susceptibility to respiratory infection, C3-deficient mice were protected against smoke-induced emphysema. Nonetheless, because of the important role of lung microbiota, future studies should examine the effects of relative immune deficiency in smoke-induced emphysema in $\mathrm{C3}^{-1-}$ mice that are concurrently infected with respiratory pathogens.

$\mathrm{C} 3$ and its activated downstream products play a role in activation of the acquired immune system during the development of several autoimmune inflammatory diseases. For instance, lupus-prone mice depleted of $\mathrm{C} 3$ are protected from the development of organ injury; also, complement C3 inhibitor, acting upon sites of complement activation, effectively ameliorates collagen-induced arthritis. ${ }^{40,41}$ Further, the activation of $\mathrm{C} 3$ is required for effective trafficking of $\mathrm{mDCs}$ from the lung to the thoracic draining lymph node during influenza virus infection. ${ }^{42}$

Our studies in $C 3^{-1-}$ mice provide new insights into complement's role in activation of lung $\mathrm{mDC}$ and the generation of increased numbers of Th17 cells following exposure to smoke. Specifically, we show here that both conventional CD4 T cells expressing the $\alpha \beta$ chain of the T-cell receptor and T cells with known regulatory function ${ }^{43}$ expressing the $\gamma \delta$ chain produce IL-17 cytokine. Normally in the lungs of mice exposed to smoke, there are a large number of $\gamma \delta$ T cells that express IL-17; mice deficient in $\gamma \delta \mathrm{T}$ cells develop exaggerated emphysema when exposed to smoke. ${ }^{10}$ In $\mathrm{C}_{3} \mathrm{ar}^{-/-}$mice exposed to smoke, we found an increase in the relative abundance of Th17 cells compared with WT mice. Relatively large numbers of Th17 cells was associated with a reduction in emphysema. This suggests that in $\mathrm{C}_{3} \mathrm{ar}^{-1-}$ mice, the presence of 
IL-17-producing $\gamma \delta \mathrm{T}$ cells may protect against smoke-induced emphysema. These findings were shown only in mice lacking $\mathrm{C} 3 \mathrm{aR}$, and not those lacking C3; the exact mechanisms that govern C3a signaling and recruitment of IL-17-producing $\gamma \delta \mathrm{T}$ cell to the lungs of mice exposed to cigarette smoke remain to be determined.

Considering that symptomatic relief of airway obstruction is the only treatment available for management of emphysema, there is great need for better understanding of the pathogenesis of smoking-induced emphysema. Now that we have shown that activation of the $\mathrm{C} 3 \mathrm{a} / \mathrm{C} 3 \mathrm{aR}$ axis plays an important role in its pathophysiology, it will be appropriate to look for agents that block $\mathrm{C} 3$ cleavage and/or suppress production or the activity of C3 fragments that can be used to treat this disease.

\section{METHODS}

Animals. WT C57BL/6 and $\mathrm{C}^{-1-}$ (C57BL/6 background) mice were purchased from the Jackson Laboratory (Bar Harbor, ME). C3ar ${ }^{-1-}$ mice were backcrossed (greater than 10 generations) to $\mathrm{C} 57 \mathrm{BL} / 6$ as previously described, ${ }^{44}$ and were bred in the transgenic animal facility at Baylor College of Medicine. All experimental protocols were approved by the Institutional Animal Care and Use Committee of Baylor College of Medicine and followed the National Research Council Guide for the Care and Use of Laboratory Animals.

Characterization of human subjects. Plasma sample and lung tissues were collected from a total of 40 non-atopic current or former smokers, serially entered into the study; all smoker subjects had significant $(>20$ pack-years) history of smoking (Supplementary Table S1). chronic obstructive pulmonary disease was diagnosed according to the criteria recommended by the National Institutes of Health-World Health Organization workshop summary and emphysema was detected on chest CT scan as previously described. ${ }^{45}$ Smoking one pack of cigarettes per day each year is defined as one "pack-year." Subjects were recruited from the chest or surgical clinics at Michael E. DeBakey Houston Veterans Affairs Medical Center hospitals. Studies were approved by the Institutional Review Board at Baylor College of Medicine, and informed consents were obtained from all patients.

Antibodies and reagents. Antibodies used for western blotting and immunohistochemistry of C3 and monoclonal anti-human complement component C3a antibody were purchased from R\&D Systems (Minneapolis, MN); mouse anti-human complement C3b-alpha monoclonal antibody for detection of $\mathrm{C} 3 \mathrm{~b}$ and $\mathrm{C} 3 \mathrm{c}$ was purchased from Chemicon, Millipore (Billerica, MA); mouse anti-human C3d were purchased from AbD Serotec (Raleigh, NC). Rabbit polyclonal antibodies for immunofluorescent and flow cytometry staining of murine C3aR was generously provided by Dr Scott Drouin from the University of Texas UT Houston Health Science Center as previously described. ${ }^{44}$ Alexa-Fluor 488 conjugated Goat anti-Rabbit IgG was purchased from Invitrogen (Grand Island, NY).

Complement protein cleavage assay and identification of its fragments. Purified human C3 (5 $\mu$ g; Complement Technology, Tyler, TX) was incubated for $4 \mathrm{~h}(\mathrm{~h})$ at $37^{\circ} \mathrm{C}$ with control (vehicle), or 0.5 , 0.05 , and $0.005 \mu \mathrm{g}$ of human NE (EMD, Calbiochem, Darmstadt, Germany), human MMP9, MMP12 (Anaspec, Fremont, CA), human cathepsin G (EMD Millipore; Billerica, MA) and human proteinase 3 (Novoprotein, Summit, NJ) in a total volume of $50 \mu$ l diluted by substrate buffer ( $50 \mathrm{mM}$ Tris, $50 \mathrm{mM} \mathrm{CaCl}_{2}$ ). Equal concentrations of cleaved (proteinase treated) and intact (control vehicle treated) C3 protein were loaded on $10 \%$ non-reducing tricine gel and resolved using electrophoresis. After separation, proteins on the gel were transferred to nitrocellulose membrane by iBlot Gel Transfer Device (Life Technologies, Grand Island, NY). After blocking in 3\% bovine serum albumin for $1 \mathrm{~h}$ at room temperature, western blotting was used to detect $\mathrm{C} 3 \mathrm{a}, \mathrm{C} 3 \mathrm{~b}-\alpha$, and $\mathrm{C} 3 \mathrm{~d}$ according to the manufacturer's instructions.

Mouse model of emphysema. Mice ( 8 weeks old) were exposed to active smoke from commercial cigarettes as described previously. ${ }^{10}$ Briefly, mice were exposed to intermittent cycles of smoke $(5 \mathrm{~s})$ followed by $20 \mathrm{~s}$ of oxygen lasting $5 \mathrm{~min}$ per cigarette. Mice were given four cigarettes, 5 days a week for a total of 6 months. Intermittent cyclic delivery of smoke was designed to mimic puffing cycles in smokers and to prevent $\mathrm{CO} 2$-induced asphyxiation. Mice were given $10 \mathrm{~min}$ of rest in between cigarettes and total cigarettes were calculated to approximate $>20$ pack-years smoke exposure in humans. ${ }^{10}$ Fortyeight hours following the last smoke exposure, mice were killed and BAL was collected by instilling and withdrawing $0.8 \mathrm{ml}$ of sterile phosphate-buffered saline (PBS) twice through the trachea. Total and differential cell counts in the BAL fluid were determined with the standard hemocytometer and HEMA3 staining (Fisher Scientifics, Waltham, MA) of 200 microliter aliquots prepared with cytospin slides. Cytokine and chemokine concentrations in the BAL were measured by Milliplex kit (EMD Millipore) according to the manufacturer's instructions.

Micro-computed tomography (microCT) and mean linear intercept. Quantification of lung emphysema in mice was determined by microCT volumetric and density measurements as previously described using the Animal Phenotyping Core in Baylor College of Medicine. ${ }^{10}$ Briefly, anesthetized mice were placed in an animal mCT scanner (Gamma Medica, Northridge, CA), and completed images of the chest were used for emphysema quantification with Amira 3.1.1 software according to the manufacturer's instructions (Amira, San Diego, CA). In addition, mean linear intercept was used as a complementary method to quantify emphysema as previously described. ${ }^{25}$

mRNA isolation and qPCR. Total RNA was extracted from mouse BAL cells with TRIzol (Invitrogen) following the manufacturer's instructions. cDNA was synthesized using RNase HRT (Invitrogen) and analyzed by using iQ SYBR Green Supermix in an iCycler (both from Bio-Rad, Hercules, CA). All gene probes, Mmp9 (Mm00600164_g1), Mmp12 (Mm00500554_m1),C3ar1 (Mm02620006_s1),Il6(Mm00446190_m1), Illbeta (Mm00434228_m1), Cd86 (Mm00444543_m1) and human C3AR1 (Hs00269693_s1) were purchased from Applied Biosystems (Carlsbad, CA). All data were normalized to $18 \mathrm{~S}$ ribosomal RNA (Hs99999901_s1) expression.

Lung APCs immune phenotype. Red blood cell (RBC)-free single-cell suspensions of the lung tissue were blocked with 2 ul per sample mouse Fc block (eBioscience, San Diego, CA) and labeled with fluorescent anti-B220, anti-CD11b, anti-CD11c, and anti-Ly6C/G antibodies (BD Biosciences, San Jose, CA), followed by detection of fluorescent signal using LSRII (BD, Franklin Lakes, NJ). Alternatively, RBC-free singlecell suspension of the lungs or BAL cells were blocked in $10 \%$ goat serum and $2 \mathrm{ul} \mathrm{Fc} \mathrm{block} \mathrm{for} 30 \mathrm{~min}$ on ice and then labeled with rabbit polyclonal antibody against mouse C3aR. Cells were washed with PBS three times and stained with Alexa Fluor-488-conjugated goat antirabbit IgG, along with primary antibodies; fluorescent signal was detected by LSRII.

In vitro T-cell co-culture and cytokine measurements. Mouse lung or spleen single-cell suspension was prepared by mincing whole organs through $40 \mu \mathrm{m}$ cell strainer (BD Falcon, Franklin Lakes, NJ) followed by RBC lysis (ACK lysis buffer) (Sigma-Aldrich, St Louis, MO) for 3 min. Lung antigen-presenting cells were isolated from RBC-free whole lung cells labeled with paramagnetic bead-conjugated antiCD11c (Miltenyi Biotec, San Diego, CA) and separated using autoMACS (Miltenyi Biotec) according to the manufacturer's instructions. Mouse splenic CD4 ${ }^{+} \mathrm{T}$ cells were isolated from RBC-free single cells suspension from WT naïve mice as described above; and lung $\mathrm{CD}_{11 \mathrm{c}^{+}} \mathrm{mDCs}$ were isolated from $\mathrm{RBC}$-free single cells 
suspension from WT, $C 3^{-1-}$, and $C 3 a r^{-1-}$ mice exposed to air or cigarette smoke. Mouse splenic $\mathrm{CD}^{+} \mathrm{T}$ cells were cultured in complete media for 3 days in vitro with congenic CD11c ${ }^{+}$lung $\mathrm{mDCs}$ (10:1 ratio, $2 \times 10^{5} \mathrm{CD} 4^{+}$T cells and $\left.2 \times 10^{4} \mathrm{mDCs}\right)$ in the presence of $1 \mu \mathrm{g} / \mathrm{ml}$ soluble anti-mouse CD3 (BD, Franklin Lakes, NJ). Milliplex kit was used to measure concentrations of a selected group of cytokines (IL-6, IL-17) according to manufacturer's instructions.

In vitro chemotaxis assay. Mouse bone marrow derived DCs (BMDCs) were differentiated using cells harvested from bone marrows of WT and C3ar ${ }^{-1-}$ mice. Briefly, mouse femurs were flushed with RPMI supplemented with $10 \%$ heat inactivated fetal bovine serum (complete media) to extract bone marrow cells. RBCs in the crude cell suspension were lysed by ACK buffer and bone marrow cells were cultured in complete media with $10 \mathrm{ng} / \mathrm{ml} \mathrm{IL-} 4$ and $20 \mathrm{ng} / \mathrm{ml} \mathrm{GM-CSF}$ for 5-7 days to derive BMDCs. ${ }^{46}$ Human monocyte derived dendritic cells were prepared from peripheral blood mononuclear cells (PBMCs) isolated from whole blood purchased from Gulf Coast Regional Blood Center. Briefly, PBMCs were purified using Ficoll-Paque Plus (GE Healthcare; Pittsburgh, PA) according to manufacturer's instruction. RBC-free PBMCs were seeded $\left(9 \times 10^{6}\right.$ cells in complete media) in 6well plates for $3 \mathrm{~h}$ at $37^{\circ} \mathrm{C}$ and then non-adherent cells were removed by washing with sterile PBS. Adherent cells were cultured in complete media supplemented with $10 \mathrm{ng} / \mathrm{ml}$ human IL-4 and $50 \mathrm{ng} / \mathrm{ml}$ human GM-CSF for 5 to 6 days. Viable cells were suspended to a final working concentration of $1 \times 10^{6}$ cells $/ \mathrm{ml}$ in RPMI and $5 \times 10^{4}$ cells were used in chemotaxis assays.

Chemotaxis was measured using 48-well chemotaxis chambers (Neuro Probe; Gaithersburg, MD) according to manufacturer's instruction. The chemotactic activity of C3a receptor agonist (CAS 944997-60-8 used at $100 \mathrm{ng} / \mathrm{ml}$; Sigma-Aldrich), BAL fluid from WT and $C 3^{-1-}$ mice exposed to air or cigarette smoke was assessed against BMDCs in triplicate as previously described. ${ }^{47}$ Briefly, BAL fluid supernatant were placed in lower chambers that were separated by 8 micron transfilters; BMDCs were placed on top chambers, and incubated at $37^{\circ} \mathrm{C}$ for $1 \mathrm{~h}$. In some experiments transfilters were harvested at 15-, 30- and 60-min time points. Transmigrating cells were enumerated at $20 \mathrm{x}$ magnification and cell numbers were reported as the average number of cells/field. ${ }^{47}$ Chemotactic activity of cleaved C3 fragments was examined using chemotaxis assays as described above. Briefly, NE- or MMP12-cleaved C3 products were purified in $\mathrm{PBS}$ using $3 \mathrm{kD}$ columns (EMD Millipore) and were used in chemotaxis assay at $5 \mu \mathrm{g} / \mathrm{ml}$ as described above.

Immunohistochemical detection of complement protein. Human lung tissue specimens from smokers with and without emphysema collected by surgical resection, were embedded into cryo-conserve media (Tissue-Tek; Torrance, CA), and $5 \mu \mathrm{m}$ lung sections were used for immune staining. Briefly, lung sections were fixed in ice-cold acetone, blocked in 5\% non-fat milk, and incubated with primary antibody for $1 \mathrm{~h}$. Lung sections were washed three times in PBST and signal was detected using fluorescent conjugated secondary antibodies. Nuclei were counter-stained with DAPI by HardSet kit (Vector Laboratories; Burlingame CA). Perfused mouse lung sections isolated from air control or smoke exposed mice were paraffin embedded. Briefly, following rehydration, and antigen retrieval, ${ }^{48}$ lung sections were subjected to immunohistochemical analyses as described above. Images were detected by a Nikon ECLIPSE TE2000 microscope using NIS-Elements software version 2.30 and Leica DFC300 FX.

Characterization of complement regulatory receptors. RBC-free single-cell suspensions of the human lung tissue were labeled with fluorescent anti-CD4, anti-CD19, anti-CD11c and anti-CD1a antibodies (BD Biosciences) to identify respectively, T cells, B cells, Macrophages and mDCs. Complement regulatory proteins, were detected using fluorescent anti-CD46, anti-CD55, anti-CD93 and anti97 (BD Biosciences), and signal was detected using LSRII (BD).
Quantification of C3 components in human plasma. C3 in heparinized human plasma was measured after samples were diluted (PBST with1\% bovine serum albumin), detected using a sandwich ELISA (GenWay Biotech, San Diego, CA), according to the manufacturer's instructions. Briefly, Immulon ELISA plates were coated with $500 \mathrm{ng} / \mathrm{ml}$ chicken IgY anti-human C3 in PBS overnight at $4{ }^{\circ} \mathrm{C}$. Plates were washed with PBST three times and blocked in $1 \%$ bovine serum albumin in PBS for $1 \mathrm{~h}$ at room temperature. Plasma samples and standards were diluted and added to the plates. After $2 \mathrm{~h}$ of incubation at room temperature, plates were washed with PBST for three times. HRP-conjugated chicken IgY anti-human C3 (20 ng/ml) was added to detect $\mathrm{C} 3$. After 1-h incubation at room temperature, plates were washed five times with PBST and developed by BD OptEIA TMB substrate (BD). Final readout was detected by absorbance at $450 \mathrm{~nm}$. Concentration of C3a in plasma samples was detected using human C3a ELISA kit (BD) according to the manufacturer's instruction.

In vitro culture and stimulation of human lung mDCs. RBC-free single-cell suspensions of the human lung tissue were first labeled with CD1a antibody-conjugated beads and then CD1a-positive cells were isolated by AutoMACS according to the manufacturer's instruction (Miltenyi Biotec). After isolation, cells were counted and adjusted to a concentration of $1 \times 10^{6} / \mathrm{ml}$. A total of $2 \times 10^{5}$ cells were plated in each well of 96-well plates in triplicate and stimulated with purified human C3a or media alone for $24 \mathrm{~h}$. Cells were then collected and lysed in TRIzol (Invitrogen) for further RNA isolation and analysis of C3AR1 expression.

Statistics. All statistical analyses were performed with the Prism software (GraphPad Software, La Jolla, CA). Data points in the figures show that the mean and error bars represent standard error of mean (s.e.m.). For the comparison of BAL cellularity and gene expression from air- and smoke-exposed mice, we used the Student's $t$ test or oneway analysis of variance (ANOVA) test. C3 components concentration in human studies was analyzed by the Mann-Whitney nonparametric test. Linear regression evaluated the relationship between plasma C3 or $\mathrm{C} 3 \mathrm{a}$ concentration and the FEV1/forced vital capacity ratio. For the comparison of CT quantifications of air- and smoke exposed mice, one-way ANOVA test with Bonferroni's multiple comparison was used. We considered differences significant when $P<0.05$.

SUPPLEMENTARY MATERIAL is linked to the online version of the paper at http://www.nature.com/mi

\section{ACKNOWLEDGMENTS}

The funding was provided by the National Institute of Health (HL117181) to F.K. and D.C. and a V.A. merit award (CX000104-05) to F.K. The project was supported in part by fellowship administered by the NIOSH to M.S. and R.Y. This project was also supported by Mouse Phenotyping Core, and the Cytometry and Cell Sorting Core at Baylor College of Medicine with funding from the NIH (Al036211, CA125123, and RR024574) and the expert assistance of Joel M. Sederstrom. We thank Han-Fang Cheng for the technical assistance.

\section{DISCLOSURE}

The authors declared no conflict of interest.

(c) 2015 Society for Mucosal Immunology

\section{REFERENCES}

1. Niewoehner, D.E., Kleinerman, J. \& Rice, D.B. Pathologic changes in the peripheral airways of young cigarette smokers. New Engl. J. Med. 291, 755-758 (1974).

2. Wright, J.L. \& Churg, A. Animal models of cigarette smoke-induced $c$ hronic obstructive pulmonary disease. Exp. Rev. Respir. Med. 4, 723-734 (2010). 
3. Houghton, A.M. Mechanistic links between COPD and lung cancer. Nat. Rev. Cancer 13, 233-245 (2013).

4. Kheradmand, F., Shan, M., Xu, C. \& Corry, D. Autoimmunity in chronic obstructive pulmonary disease: clinical and experimental evidence. Exp. Rev. Clin. Immunol. 8, 285-292 (2012).

5. Maes, T. et al. Murine TLR4 is implicated in cigarette smoke-induced pulmonary inflammation. Int. Arch. Allergy Immunol. 141, 354-368 (2006).

6. Doz, E. et al. Cigarette smoke-induced pulmonary inflammation is TLR4/ MyD88 and IL-1R1/MyD88 signaling dependent. J. Immunol. 180, 1169-1178 (2008).

7. Phipps, J.C. et al. Cigarette smoke exposure impairs pulmonary bacterial clearance and alveolar macrophage complement-mediated phagocytosis of Streptococcus pneumoniae. Infect. Immun. 78, 1214-1220 (2010).

8. Stampfli, M.R. \& Anderson, G.P. How cigarette smoke skews immune responses to promote infection, lung disease and cancer. Nat. Rev. Immunol. 9, 377-384 (2009).

9. Lee, S.-H. et al. Antielastin autoimmunity in tobacco smoking-induced emphysema. Nat. Med 13, 567-569 (2007).

10. Shan, M. et al. Cigarette smoke induction of osteopontin (SPP1) mediates $\mathrm{T}(\mathrm{H}) 17$ inflammation in human and experimental emphysema. Sci. Transl. Med. 4, 117 ra119 (2012).

11. Kurimoto, E. et al. IL-17A is essential to the development of elastase-induced pulmonary inflammation and emphysema in mice. Respir. Res. 14, 5 (2013).

12. Xu, C. et al. Autoreactive T cells in human smokers is predictive of clinical outcome. Front. Immunol. 3, 267 (2012).

13. Eppert, B.L., Wortham, B.W., Flury, J.L. \& Borchers, M.T. Functional characterization of $\mathrm{T}$ cell populations in a mouse model of chronic obstructive pulmonary disease. J. Immunol. 190, 1331-1340 (2013).

14. Chang, Y. et al. Genetic deletion of IL-17A reduces cigarette smokeinduced inflammation and alveolar type II cell apoptosis. Am. J. Physiol. 306, L132-L143 (2014).

15. Zhang, J. et al. Increased expression of CD4 + IL-17 + cells in the lung tissue of patients with stable chronic obstructive pulmonary disease (COPD) and smokers. Int. Immunopharmacol. 15, 58-66 (2013).

16. Shan, M. et al. Lung myeloid dendritic cells coordinately induce $\mathrm{TH} 1$ and TH17 responses in human emphysema. Sci. Transl. Med. 1, 4ra10 (2009).

17. Holers, V.M. Complement and its receptors: new insights into human disease. Annu Rev. Immunol 32, 433-459 (2014).

18. Sacks, S.H. \& Zhou, W. The role of complement in the early immune response to transplantation. Nat. Rev. Immunol. 12, 431-442 (2012).

19. Zipfel, P.F. \& Skerka, C. Complement regulators and inhibitory proteins. Nat. Rev. Immunol. 9, 729-740 (2009).

20. Drouin, S.M., Corry, D.B., Hollman, T.J., Kildsgaard, J. \& Wetsel, R.A. Absence of the complement anaphylatoxin C3a receptor suppresses Th2 effector functions in a murine model of pulmonary allergy. J. Immunol. 169, 5926-5933 (2002)

21. Walters, D.M., Breysse, P.N., Schofield, B. \& Wills-Karp, M. Complement factor 3 mediates particulate matter-induced airway hyperresponsiveness. Am. J. Resp. Cell Mol. Biol. 27, 413-418 (2002).

22. Li, K. et al. Functional modulation of human monocytes derived DCs by anaphylatoxins C3a and C5a. Immunobiology 217, 65-73 (2012).

23. Hawlisch, H., Wills-Karp, M., Karp, C.L. \& Kohl, J. The anaphylatoxins bridge innate and adaptive immune responses in allergic asthma. Mol. Immunol. 41, 123-131 (2004).

24. Robbins, R.A., Nelson, K.J., Gossman, G.L., Koyama, S. \& Rennard, S.I. Complement activation by cigarette smoke. Am. J. Physiol. 260, L254L259 (1991).

25. Shan, M. et al. Agonistic induction of PPARgamma reverses cigarette smoke-induced emphysema. J. Clin. Invest 124, 1371-1381 (2014).

26. Ghannam, A. et al. Human C3 deficiency associated with impairments in dendritic cell differentiation, memory $\mathrm{B}$ cells, and regulatory $\mathrm{T}$ cells. J. Immunol. 181, 5158-5166 (2008).

27. Maddur, M.S., Miossec, P., Kaveri, S.V. \& Bayry, J. Th17 cells: biology, pathogenesis of autoimmune and inflammatory diseases, and therapeutic strategies. Am. J. Pathol. 181, 8-18 (2012).
28. Claesson, R., Kanasi, E., Johansson, A. \& Kalfas, S. A new cleavage site for elastase within the complement component 3. APMIS 118, 765-768 (2010).

29. Del Nagro, C.J., Kolla, R.V. \& Rickert, R.C. A critical role for complement C3d and the B cell coreceptor (CD19/CD21) complex in the initiation of inflammatory arthritis. J. Immunol. 175, 5379-5389 (2005).

30. Miller, R.D., Kueppers, F. \& Offord, K.P. Serum concentrations of C3 and C4 of the complement system in patients with chronic obstructive pulmonary disease. J. Lab. Clin. Med. 95, 266-271 (1980).

31. Kosmas, E.N., Zorpidou, D., Vassilareas, V., Roussou, T. \& Michaelides, S. Decreased C4 complement component serum levels correlate with the degree of emphysema in patients with chronic bronchitis. Chest 112, 341-347 (1997).

32. Shah, R.S. \& Cole, J.W. Smoking and stroke: the more you smoke the more you stroke. Exp. Rev. Cardiovasc. Ther. 8, 917-932 (2010).

33. Van Eeden, S., Leipsic, J., Paul Man, S.F. \& Sin, D.D. The relationship between lung inflammation and cardiovascular disease. Am. J. Resp. Crit. Care Med. 186, 11-16 (2012).

34. Vlahos, R. \& Bozinovski, S. Recent advances in pre-clinical mouse models of COPD. Clin. Sci. 126, 253-265 (2014).

35. Dhami, R. et al. Acute cigarette smoke-induced connective tissue breakdown is mediated by neutrophils and prevented by alpha1antitrypsin. Am. J. Resp. Cell Mol. Biol. 22, 244-252 (2000).

36. Tichaczek-Goska, D. Deficiencies and excessive human complement system activation in disorders of multifarious etiology. Adv. Clin. Exp. Med. 21, 105-114 (2012).

37. Matsuyama, W. et al. Molecular analysis of hereditary deficiency of the third component of complement (C3) in two sisters. Intern. Med. 40, 1254-1258 (2001).

38. Prodeus, A.P., Zhou, X., Maurer, M., Galli, S.J. \& Carroll, M.C. Impaired mast cell-dependent natural immunity in complement C3-deficient mice. Nature 390, 172-175 (1997).

39. Wessels, M.R. et al. Studies of group B streptococcal infection in mice deficient in complement component $\mathrm{C} 3$ or $\mathrm{C} 4$ demonstrate an essential role for complement in both innate and acquired immunity. Proc. Natl. Acad. Sci. U S A 92, 11490-11494 (1995).

40. Song, H., Qiao, F., Atkinson, C., Holers, V.M. \& Tomlinson, S. A complement C3 inhibitor specifically targeted to sites of complement activation effectively ameliorates collagen-induced arthritis in DBA/1J mice. J. Immunol 179, 7860-7867 (2007).

41. Ioannou, A., Lieberman, L.A., Dalle Lucca, J.J. \& Tsokos, G.C. Complement depletion protects lupus-prone mice from ischemia-reperfusioninitiated organ injury. Am. J. Physiol. Gastrointest. Liver Physiol. 304, G283-G292 (2013).

42. Kandasamy, M. et al. Complement mediated signaling on pulmonary CD103(+) dendritic cells is critical for their migratory function in response to influenza infection. PLoS Pathog. 9, e1003115 (2013).

43. Bonneville, M., O'Brien, R.L. \& Born, W.K. Gammadelta T cell effector functions: a blend of innate programming and acquired plasticity. Nat. Rev. Immunol. 10, 467-478 (2010).

44. Dillard, P., Wetsel, R.A. \& Drouin, S.M. Complement C3a regulates Muc5ac expression by airway Clara cells independently of Th2 responses. Am. J. Resp. Crit. Care Med. 175, 1250-1258 (2007).

45. Hesselbacher, S. et al. Cross-sectional analysis of the utility of pulmonary function tests in predicting emphysema in ever-smokers. Int. J. Environ. Res. Public Health 8, 1324-1340 (2011).

46. Inaba, K., Swiggard, W.J., Steinman, R.M., Romani, N. \& Schuler, G. Isolation of dendritic cells. Curr. Protoco. Immunol. Chapter 3, Unit 37 (2001).

47. Corry, D.B. et al. Decreased allergic lung inflammatory cell egression and increased susceptibility to asphyxiation in MMP2-deficiency. Nat. Immunol. 3, 347-353 (2002).

48. Goswami, S. et al. Divergent functions for airway epithelial matrix metalloproteinase 7 and retinoic acid in experimental asthma. Nat. Immunol. 10, 496-503 (2009). 